The University of Maine

DigitalCommons@UMaine

Publications

Senator George J. Mitchell Center for Sustainability

Solutions

$12-2012$

\title{
Does Green Consumerism Increase the Acceptance of Wind Power?
}

Caroline L. Noblet

University of Maine, caroline.noblet@maine.edu

John Thøgersen

Follow this and additional works at: https://digitalcommons.library.umaine.edu/ mitchellcenter_pubs

Part of the Behavioral Economics Commons, and the Environmental Studies Commons

\section{Repository Citation}

Noblet, Caroline L. and Thøgersen, John, "Does Green Consumerism Increase the Acceptance of Wind Power?" (2012). Publications. 83.

https://digitalcommons.library.umaine.edu/mitchellcenter_pubs/83

This Article is brought to you for free and open access by DigitalCommons@UMaine. It has been accepted for inclusion in Publications by an authorized administrator of DigitalCommons@UMaine. For more information, please contact um.library.technical.services@maine.edu. 


\section{Does green consumerism increase the acceptance of wind power?}

John Th $ø$ gersen $^{\mathrm{a},{ }^{*}}$, Caroline Noblet ${ }^{\mathrm{b}}$

aarhus University, School of Business and Social Sciences, Department of Business
Administration, Bartholins Alle' 10, Bld. 1323, DK-8000 Aarhus C, Denmark
b University of Maine, School of Economics, 5782 Winslow Hall, Orono, ME 04469, USA
Corresponding author. Tel.: p45 8716 5008. fax: p45 86153967.

E-mail addresses: jbt@asb.dk (J. Thøgersen), caroline.noblet@maine.edu (C. Noblet). 


\section{ABSTRACT}

In this paper, we discuss what might be termed an action-based learning approach to promoting important pro-environmental actions, such as support for or acceptance of environmental policy. Such an approach involves promoting simple and easy behaviours as entry points for more radical steps towards sustainability, referred to as "catalytic" or "wedge" behaviours. Despite the obvious need for innovative approaches to promote important pro-environmental behaviour, and sound theoretical backing for such concepts, there is a lack of research testing the key propositions of this approach. In a survey study based on a random sample of residents of the state of Maine, USA, we find that both everyday "green" behaviour and the acceptance of an expansion of wind power are rooted in environmental concern and that everyday "green" behaviour gives a significant contribution to predicting acceptance of wind power when controlling for environmental concern. Hence, the promotion of everyday "green" behaviours may prepare the grounds for increasing acceptance of more far-reaching changes in the population, such as an expansion of wind power.

KEYWORDS: Spillover, Wind power, Green consumerism 


\section{INTRODUCTION}

In recent years, there has been increasing focus on the extent to which the small and simple steps that many people take for the environment in everyday life, and which are in and off themselves arguably relatively inconsequential (Crompton, 2008), can function as a lever or "wedge" for changes that are more important for environmental sustainability (Defra, 2008; Dietz et al., 2009; Thøgersen and Crompton, 2009). Indeed, Thøgersen and Crompton (2009) argue that it only makes sense for governments and environmental organizations, which are well aware that fundamental changes in behaviour are urgently needed, to campaign for behaviour changes with small environmental impacts if they expect that the simple behavioural changes will lead to more far-reaching and environmentally significant changes.

One of these fundamental "behaviour changes," according to Thøgersen and Crompton (2009), is acceptance of environmental policy, including government enacted infrastructure changes, required to mitigate climate change and other serious environmental threats.

"It is ... crucially important to examine the effect of public campaigns aimed at encouraging individuals to modify their behaviour in simple ways that serve to reduce personal environmental impact: to what extent do such campaigns contribute to building public acceptance of, and demand for, far-reaching government interventions?" (Thøgersen and Crompton 2009, p.142) However, despite the importance of the issue, we are not aware of any studies investigating whether doing small and simple things for the environment in everyday life has any implications for people's support for or acceptance of more radical structural changes, which are decided at the political level.

It should be added that it is not a trivial question whether there is such a "spillover" effect 
(Thøgersen, 1999), nor whether such an effect would necessarily be positive. It is sometimes suggested that people may perform small or simple, but inconsequential "green" behaviours in order to justify to themselves or others refusal to make more consequential changes in their lifestyle (Crompton, 2008). There is even research suggesting that performing a "green" behaviour may sometimes function as a license to act in an unethical way later (Mazar and Zhong, 2010). The latter research has been justly criticized for lacking validity outside the university laboratory. But still, it emphasizes the need for research that in a systematic way investigates whether small and simple "green" consumer behaviours can be used as a "wedge" for acceptance of (or rather are a source of opposition to) more radical structural changes.

In this paper, we take a closer look at what might be termed an action-oriented learning approach to promoting important pro-environmental actions, such as support for or acceptance of environmental policy. Such an approach was recently proposed by the UK government's Department for Environment, Food and Rural Affairs: "to promote a range of behaviours as entry points in helping different groups to make their lifestyles more sustainable-including catalytic (or "wedge") behaviours" (Defra, 2008, p. 22). Despite the obvious need for innovative approaches to promote important pro-environmental behaviour, and sound theoretical backing for such concepts (Thøgersen, 1999; Thøgersen and Crompton, 2009), there is still a lack of research on this approach.

\section{PREVIOUS RESEARCH}

\section{Overview}

Scientists and some members of the environmental movement have expressed concern that the simple and painless changes in everyday behaviour that are often advocated in environmental 
campaigns do not match the challenges that we are facing. As expressed by physicist David McKay: "Have no illusions. To achieve our goal of getting off fossil fuels, these reductions in demand and increases in supply [of renewables] must be big. Do not be distracted by the myth that "every little helps." If everyone does a little, we'll achieve only a little. We must do a lot. What's required are big changes in demand and in supply." (McKay, 2008, p. 114, emphasis in original).

Still, it makes sense for governments and environmental organizations to advocate simple and painless changes in everyday behaviour if the simple behavioural changes lead to more far-reaching and environmentally significant changes. For example, some environmental communications consultancy companies build on the well-researched "foot-in-the-door" technique in their environmental campaigning (Freedman and Fraser, 1966). The crux of this technique is to "[g]et someone to do something small and then introduce another larger action once the small one is completed" (Futerra, 2006, p. 10). However, a recent review of the scientific literature on this subject did not find much evidence to back the assumption that doing one simple thing for the environment increases the likelihood that a person will move on to more and bigger things or, rather, the evidence is weak and equivocal (Thøgersen and Crompton, 2009).

A range of psychological theories lend support to the idea that people who start to do things for the environment are likely to move on to do more, perhaps bigger and more difficult thing, including goal theory (Dhar and Simonson, 1999; Glasman and Albarracín, 2006; Knussen et al., 2004), self-perception theory (Bem, 1972), cognitive dissonance theory (Festinger, 1957; Thøgersen, 2004), and various learning theories (Nigg et al., 1999). However, the empirical research on this phenomenon is inconclusive. Most of the empirical studies are based on a single, 
questionnaire-based survey, which is used to identify correlations between different pro-environmental behaviours (e.g., Bratt, 1999; Thøgersen, 1999; Verhoef, 2005). The main problem with this method is that a correlation does not prove that doing one of the correlated behaviours influences the likelihood of doing the other. Instead, a correlation may, for example, be the result of both activities depending on a common third factor, such as holding certain values, skills or resources (Thøgersen and O" lander, 2006). In this case, it is not one activity that leads to the other, but the values, skills or resources that explain both.

Much stronger evidence can be obtained by using a panel study, repeating the same survey with the same representative sample from a given population. One such study collected a series of three interviews over a two-year period with a representative sample of Danish residents (Thøgersen and Olander, 2003). The study tracked the development in people's lifestyles in three different environmentally relevant areas: recycling, buying organic food, and using non-car modes of transportation. The aim was to investigate if behaving in a pro-environmental way in one of these areas at one time point increases (or decreases) pro-environmental action in other areas at a later time. The results suggest that there is such a tendency, but it is weak and contingent on people holding relatively strong pro-environmental values and norms.

Goal theory

Research on goal activation has shown that actions can activate goals in the mind of the actor that guide subsequent choices in the direction of attaining the activated goal. Performing a goal-directed behaviour, in the absence of any external encouragement, makes the supporting attitudes more accessible from memory and therefore more predictive of behaviour (Glasman and Albarracin, 2006; Knussen et al., 2004). Also, deliberate action to reach a goal 
(pro-environmental or not) is likely to increase the salience of the goal in the mind of the actor (e.g., Dhar and Simonson, 1999). The more salient a goal, the more likely it is that individuals will notice the relevance of their other behaviours to the same goal, thus increasing the likelihood that they will act in a goal-consistent way in these areas as well (Ratneshwar et al., 2001).

According to this stream of research, the essential prerequisite for the spillover of pro-environmental behaviour is the activation of a pro-environmental goal. The working of this mechanism is supported by empirical research on pro-environmental goal priming, by linking it to behaviour or in other ways. For example, in a study of consumer choices in a virtual supermarket, priming pro-environmental values at the entrance of the supermarket by means of pictures of nature made shoppers significantly more likely to buy organic food products (Biel et al., 2005). In another study, environmental values were primed by means of a word task, which enhanced attention to and the weight of information related to those values (Verplanken and Holland, 2002). Again, the priming of pro-environmental values resulted in significantly more environmentally friendly consumer choices, but only if these values were central to the person's self-concept.

This research shows that if acting in a way that benefits the environment primes or activates a more general environmental goal, this would increase the likelihood that the person notices other ways to respond towards that goal and thereby the likelihood that he or she performs other pro-environmental behaviours. The priming of environmental goals presumably requires that environmental reasons for performing the initial behaviour are salient.

The latter point was demonstrated in a recent study, finding in two laboratory experiments that participants were more likely to recycle a sheet of paper when they had been reading environmental information about another pro-environmental behaviour (car-sharing), but not 
when they had been reading financial information (Evans et al., In press). It was inferred that thinking about the initial behaviour activated pro-environmental values and goals, but only when the links between the initial behaviour and environmental reasons for performing it were made salient.

Does "foot in the door" apply?

There is also relevant evidence from experimental research testing the "foot-in-the-door" approach to behaviour change. A thorough statistical analysis of this research found that the foot-in-the door phenomenon, although replicable, is weak and not nearly as robust as often assumed (Beaman et al., 1983). However, recent research suggests that a foot-in-the-door effect exists, but that it is contingent on the initial, small action being perceived as "diagnostic of a pro-environmental disposition" (Cornelissen et al., 2007; Cornelissen et al., 2008).

The basic proposition is that the foot-in-the-door effect (i.e., spillover) happens because performing a behaviour (i.e., the initial, small action) activates a latent pro-environmental disposition in the person, which then makes it more likely that the person will act in a pro-environmental way when facing the second request or opportunity. However, according to Cornelissen et al., the first behaviour only activates a pro-environmental disposition if the actor perceives it as "diagnostic" of that disposition. Generally, an action is perceived as more diagnostic if it is less common and more unambiguously attributed to a wish to benefit the environment. When a certain way of acting has become the general norm, such as recycling or turning off the water when you brush your teeth, it is less diagnostic for inferring pro-environmental values and attitudes than are less common behaviours, such as installing solar panels on your roof or taking the train instead of flying to another state (or, in Europe, to another 
country). Also, many pro-environmental actions are ambiguous in the sense that they produce both environmental and private benefits. Think, for example, on the obvious private benefits of climate friendly activities such as bicycling, saving electricity, and cutting down on meat. That the most common small and simple steps that people can take for the environment lacks "diagnosticity," because they are either the general norm or ambiguous, may be one of the reasons why pro-environmental "spillover" seems to be such a slow and weak process.

A promising result from this line of research is that it is possible to enhance the perceived diagnosticity of common or ambiguous environment-friendly behaviours by means of social marketing techniques. It seems that communication that "frames" an ambiguous action (i.e., one with both environmental and private benefits) as reflective of a pro-environmental disposition or that cues common pro-environmental actions as environmentally friendly can make people doing these acts commit to do more for the environment.

Does going green make you mean?

At least in principle there is also the opposite possibility, that doing something for the environment reduces the likelihood that a person will also do something more, small or big. Thøgersen and Crompton (2009) refer to this phenomenon as "negative spillover." It has even been suggested that "going green may make you mean." However, although there is experimental evidence that some individuals in some situations might feel they had a license to do immoral things after having bought "green" products (Mazar and Zhong, 2010), the tested experimental conditions are very special and unlikely to be ever met outside the laboratory (Thøgersen, 2011). Hence, we are not aware of evidence suggesting that moral licensing leads to negative spillover between pro-environmental behaviours, in practice. 
Actually, there seem to be considerably stronger reasons to expect a related, but substantially different phenomenon: that people who have done something for the environment may feel that they have already done "their fair share" due to a combination of a contribution ethic and people's self-serving biases (Thøgersen and Crompton, 2009). For example, in one study it was found that, although the two behaviours were positively correlated, the more people recycled the less they felt obliged to pay attention to over-packaging in the purchase situation (Thøgersen, 1999). In this case, it seemed that heavy recyclers felt that they had already made their fair contribution to solving the waste problem. However, they still routinely paid more attention to over-packaging than non-or light recyclers. Hence, at the moment we are not aware of any evidence suggesting that the effect of this mechanism is strong enough, in practice, to lead to negative spillover either.

Most evidence pertaining to the question of negative spillover is descriptive survey studies of several pro-environmental behaviours based on random samples of the general public. If the more people do one thing for the environment (say, recycle) the less they tend to do something else (say, save energy), this should lead to a negative correlation between different behaviours (say, recycling and saving energy). However, it is extremely rare that studies report negative correlations between pro-environmental behaviours (see e.g., Bratt, 1999; Kaiser and Wilson, 2004; Kim and Kim, 2010; Stern et al., 1999; Thøgersen and Olander, 2006).

A study of car-owners in Sweden found that owners of an eco-innovative car are less willing to curtail their driving than owners of a conventional car (Jansson et al., 2010). This could be due to negative spillover if an eco-innovative car is perceived to give the owner a license to drive more or it creates the perception that the owner has already done his or her "fair share." However, the finding could also be due to owners of an eco-innovative car having already curtailed their 
driving more than owners of conventional cars and therefore having less room for further curtailment. Another possibility is that some have bought an eco-innovative car exactly because they find it more difficult than others to curtail their driving.

In sum, the existing evidence does not suggest that negative spillover effects reign for individuals who have done small and simple things for the environment. However, neither is there currently much evidence to support the hope that a sustainable lifestyle will grow gradually and automatically from the successful promotion of the many small and painless steps that people can take for the environment.

From correlation to causality

A large number of studies report positive correlations between pro-environmental behaviours (Thøgersen and Crompton, 2009). Behaviours within the same taxonomic categories (the time and place of the behaviour, the skills employed, etc.) tend to be more strongly correlated than behaviours within different taxonomic categories (e.g., Stern et al., 1999; Thøgersen and Olander, 2001). Correlations between pairs of pro-environmental behaviours increase with the similarity (Bratt, 1999) or with the perceived similarity (Thøgersen, 2004) of the two behaviours. Obviously, a positive correlation between two behaviours, say an everyday "green" behaviour and support for a proposed environmental policy, does not prove that adoption of one of these behaviours (e.g., a simple, everyday "green" behaviour) increases the likelihood that the individual will also adopt the other (e.g., support for an environmental policy). A number of requirements need to be fulfilled before it is justified to speak about causality. What these requirements are is up for debate, but according to most accounts, two key ones are that 
correlation is not the product of a "third factor" influencing both of the correlated behaviours, including possible statistical artefacts (e.g., halo or priming effects).

In this particular case, it seems obvious that correlations between pro-environmental behaviours could be caused by people who are aware of and concerned about environmental problems being more likely to adopt both behaviours (say, both perform everyday "green" behaviours and support environmental policy) (Thøgersen and Olander, 2006). Hence, in order to substantiate any speculations about causality, problem awareness (i.e., environmental concern) would need to be controlled. We will explain how we did that in the following, as well as our efforts to assure that the presumed causes precede the presumed effects and to minimize risks of statistical artefacts.

The promotion of wind power-Overcoming "NIMBYism"

When it comes to preventing climate change, some of the most radical structural changes involve replacing fossil fuel based energy production with renewable energy. Currently, one of the most rapidly expanding forms of renewable energy is wind power (GWEC, 2011). However, in many countries, the expansion of wind power is hampered by reservations or even resistance in the population against wind turbines, especially wind farms, both on land and off shore (e.g., Firestone et al., 2009; Keller, 2010). For example, in Massachusetts, USA, the Cape Wind project was delayed for years due to organized resistance against the proposal. In the UK, a study of applications for onshore wind farms over an 18 month period in 2006-2007 found that two out of three applications were rejected. Therefore, wind power operators called for action "to win over a 'not in my back yard' element campaigning against new projects" (Russell, 2008). Hence, it is important for the future expansion of wind power to be able to overcome resistance and gain 
public acceptance (Bell et al., 2005; Bosley and Bosley, 1988; Wolsink, 2007). To achieve this aim, deep knowledge of the sources and contingencies of resistance, as well as of social acceptance and support, is needed (Breukers and Wolsink, 2007; Haggett, 2011; Jobert et al., 2007; van der Horst, 2007).

A diverse range of contingencies for the general public's acceptance of wind power have been studied already, from residency and place identity (Devine-Wright, 2005; Johnston et al., 2003), the type of landscape where a project is planned (Pasqualetti, 2011; van der Horst, 2007) to perceptions of distributional and procedural justice (Gross, 2007). However, as expressed by the editors of a recent special issue, "we are still at an early point of maturity in this emerging field" (Wüstenhagen et al., 2007, p. 2689). Among a range of other issues, they called for more research on the causes and contingencies of social acceptance of wind power.

In this article, we explore the empirical foundation of what might be termed "an action-based learning approach" (Reynolds and Vince, 2004) to the acceptance of wind power, among other important pro-environmental actions. Specifically, we investigate the implications of doing small and simple things for the environment in everyday life (sometimes referred to as "green consumerism," e.g., Mazar and Zhong, 2010; Moisander, 2007)on the public's acceptance of wind power. In this study, we control for problem awareness (i.e., environmental concern); a factor which is most likely a necessary, but not a sufficient condition for acceptance (Marques and Fuinhas, 2011). Hence, we investigate whether green consumerism has any implications for support or acceptance of wind power over and above just being environmentally concerned. We investigate these questions using the acceptance of an expansion of wind power in the state of Maine, USA, as our case. 
It is generally assumed that, at least in a democratic society, policy support and acceptance is a function of problem awareness. For example, Moser (2010, p. 36) argues that, "it is unlikely that policy-makers at any level or the wider public come to support a comprehensive climate policy (involving the equally necessary components of mitigation and adaptation) at the level required to substantially reduce greenhouse gas concentrations if they do not have a much clearer picture of the urgency of the situation." This assertion is supported by empirical research showing that acceptance of travel demand management measures, such as an increased tax on fuel, depends on the person's problem awareness (Eriksson et al., 2006). In research in the environmental field, problem awareness is often referred to as environmental concern (Fransson and Gärling, 1999). Hence, we hypothesize that,

H1. The support or acceptance of an expansion of renewable energy, including wind power, depends on the person's problem awareness or environmental concern.

Environmentally concerned individuals are not only more likely to support or accept environmental protection policy, but also to do a range of other things pointing towards the same goal, including everyday "green consumerism" actions, such as recycling and buying eco-labelled products (Stern et al., 1999; Thøgersen and Olander, 2006). Hence, we hypothesize that,

H2. "Green consumerism" also depends on environmental concern.

One of the primary goals of environmental campaigning is to increase popular awareness of the serious environmental threats that we are facing, or environmental concern (e.g., Crompton, 2008). On the other hand, communication researchers attest to how extremely difficult it is to 
build a proper understanding in the public about these issues (Moser, 2010) and the unfortunate "gap" between environmental concern and behaviour that Dunlap and van Liere (1978) noted in their seminal article on the New Ecological Paradigm has certainly not become narrower over the years (e.g., Barr, 2006; van Trijp and Fischer, 2011). Experience from health research suggest that people may be more likely to perform specific actions towards a superordinate goal if they have already performed other actions towards that goal, a type of action-based learning (Nigg et al., 2002; Nigg et al., 1999; Noar et al., 2008; Tucker and Reicks, 2002). Hence, we hypothesize that,

H3: Compared to other, equally concerned individuals, more active "green consumers" are more likely to accept an expansion of wind power.

Hypothesis 3 implies that "green consumerism" gives an additional contribution to the explanation of support or acceptance of wind power, after controlling for environmental concern. When combined, the three mentioned hypotheses further imply that the effect of environmental concern (the initial variable) on the acceptance of wind power (the outcome) is at least partly mediated through "green consumerism" (the mediator).

Baron and Kenny (1986) proposed four steps in a mediation analysis. If these steps are met, the data are consistent with the hypothesis that "green consumerism" (the mediator) at least partially mediates the relationship between environmental concern and the acceptance of wind power. However, only if it is possible to rule out other models that are consistent with the data can one conclusively establish that mediation has occurred.

Step 1: Establish that there is an effect that may be mediated by showing that the initial variable is significantly related to the outcome. We do this when testing $\mathrm{H} 1$. 
Step 2: Show that the initial variable is significantly related to the mediator. We do this when testing $\mathrm{H} 2$.

Step 3: Show that the mediator affects the outcome variable while controlling for the initial variable. We do this when testing $\mathrm{H} 3$.

Step 4: Establish whether the mediator completely mediates the relationship between the initial variable and the outcome, implying that the effect of the initial variable on the outcome while controlling for the mediator should be zero. If the path from the initial variable to the outcome is reduced in absolute size but is still different from zero when the mediator is introduced, this is a case of partial mediation. In the present case, we expect partial rather than full mediation since "green consumerism" is obviously not a necessary step on the path from environmental concern to acceptance of wind power.

In the case of partial mediation, the total effect of the initial variable on the outcome is divided into a direct effect and a mediated or indirect effect. The indirect effect is the product of the effect of the initial variable on the mediator and the effect of the mediator on the outcome. Contemporary mediational analyses focus mostly on the indirect effect.

H4. "Green consumerism" at least partly mediates the effect of environmental concern on support for or acceptance of an expansion of wind power.

METHODS 
The study is based upon a state-wide survey of randomly selected residents of Maine, U.S.A., 18 years old or older. The survey was administered in a two-round modified Dillman method between April and August of 2010 (Dillman et al., 2009). Each round after the initial introduction letter presented the participant with a copy of the survey, a reminder letter and a one-dollar cash incentive; the response rate was $47 \%$. On key demographic characteristics, our respondents are similar to the Maine population, but are more likely to be male, older and have a higher income: men/women 57/43\% mean age 57 y.o. (State of Maine 44 y.o.), mean income $\$ 64,000$ (State of Maine $\$ 48,000)$.

Survey design

The survey consisted of five various versions of the questionnaire which allowed for the exploration of different knowledge and perceptions regarding the diverse types of wind power under consideration in Maine: land-based and off-shore (both shallow-water and deep-water). Respondents who received one version of the survey may have been asked to consider the potential benefits and concerns of land-based wind power, while other recipients may have been asked to consider deep-water wind power during the survey. These questions are inconsequential for the present purpose and will not be discussed further in the paper.

The two versions of the survey instrument used for this analysis consisted of five sections. Section 1 solicited respondents' background knowledge about wind energy in Maine. In Section 2 respondents were asked to express their views on potential benefits and concerns of wind power. Section 3 contained alternative message framings about wind energy potential in Maine. Section 4 collected information on respondents' environmental and other attitudes and behaviours, including responses to the New Ecological Paradigm question set (Dunlap et al., 
2000). The final section consisted of demographic questions.

Variables

The survey instruments contained questions about acceptance of wind power, green consumerism and environmental concern, in that order. These questions were mixed with questions not used for the present article. All responses were made on a 7-point (acceptance of wind power) or a 5-point scale (green consumerism and environmental concern). By asking questions about acceptance of wind power (a future-oriented perspective) before questions about its presumed antecedents (here-and-now concerns and past behaviour), we avoid potential context effects (e.g. halo or priming effects) from the latter to the former question(s) (Rasinski et al., 2012).

Acceptance of wind power

Acceptance of wind power was measured by means of three items: (1) "How do you feel about wind energy?" ( $0=$ negative, 6=positive), (2) "In your opinion [emphasis in questionnaire], is wind power a good solution for Maine's energy problems?" ( $0=$ not a good solution, $6=a$ very good solution), and (3) "Would you encourage wind power development in Maine?" (0=not likely, 6=very likely). (Cronbach's Alpha=.95).

Green consumerism

Green consumerism was measured by means of three items: "How often do you ...: (1) buy 
eco-labelled products, (2) recycle, (3) buy energy efficient products?" (1=never, 3=sometimes, 5=always). (Cronbach's Alpha=.65).

Environmental concern

For measuring environmental concern, we wanted to use an instrument that was well validated in previous research, yet was adapted to the present case. One of the most popular instruments to measure environmental concern is the New Ecological Paradigm (NEP) scale, developed by Dunlap and van Liere (1978) and later revised and refined several times (Dunlap, 2008). Hence, in the questionnaire we included items from the newest version of the NEP instruments as well as items focusing on concern about climate change, air pollution in Maine, etc. We used exploratory factor analysis to identify items in this item pool contributing to a unidimensional instrument for measuring environmental concern. Our final instrument contains six items, four of which were taken from the NEP instrument: (1) "We are approaching the limit of the number of people the earth can support," (2) "If things continue on their present course, we will soon experience an ecological catastrophe," (3) "The earth is like a spaceship with very limited room and resources," (4) "The so-called 'Ecological Crisis' facing humankind has been greatly exaggerated (reversed)," (5) "I am concerned about the effect of global warming on Maine" and (6) "I am concerned about Maine's air quality" (1=strongly disagree, 3=unsure, 5=strongly agree). (Cronbach's Alpha=.84).

Statistical method

AMOS 16 (Arbuckle, 2006) was used for the structural equation modelling (SEM). The main advantage of SEM is that it is possible to explicitly account for measurement error when a latent 
variable of interest is represented by multiple manifest variables. Measures of how well the implied variance-covariance matrix, based on the parameter estimates, reflects the observed sample variance-covariance matrix can be used to determine whether the hypothesized model gives an acceptable representation of the analysed data. The usual assumptions about uncorrelated unique ("error") terms and a simple structure factor pattern in the measurement model were applied.

RESULTS

Correlations between latent variables

The first step in our data analysis is a confirmatory factor analysis (CFA) of the items used to measure the latent constructs shown in Fig. 1. The main results of the CFA are reported in Table 1.

A few comments on the most important information in the table suffice here. Notice first that the fit indices suggest an acceptable fit of the model to the data. The significant chi-square shows that the fit is not perfect, but with a sample of this size the chi-square is usually significant. More importantly, both the CFI and the RMSEA are within the normally accepted limits (Bollen, 1989). Notice next that all the bivariate correlations between the latent variables that are included in the model are positive and statistically significant. This is consistent with our hypotheses.

Structural equation modelling

Next we analyse a structural equation model for predicting acceptance of wind power in Maine, 
using the CFA model reported in Table 1 as a measurement model and combining it with the structural model illustrated in Figure 1. Hence, we model the acceptance of wind power as co-determined by environmental concern and green consumerism and green consumerism as determined by environmental concern. The main results of this analysis are reported in Table 2 .

Notice first that the fit indices for the SEM model are the exact same as for the CFA model in Table 1. This is because this SEM model basically puts the same restrictions on the data set as the CFA. The SEM model only differs from the CFA model in that the bi-directional relationships (i.e., correlations) between latent constructs have been replaced by uni-directional structural relationships (i.e., regression weights).

According to the R-squares reported in Table 2, the model explains a substantial share of the variance in both dependent variables. All regression coefficients are significant, po.001. Specifically, consistent with hypothesis $\mathrm{H} 1$ to $\mathrm{H} 3$, both environmental concern and green consumerism contribute positively to the prediction of acceptance of wind power, also when the other variable is controlled. Also, consistent with hypothesis $\mathrm{H} 2$, green consumerism depends on environmental concern in the expected way. Finally, the indirect effect reported in Table 2 shows that green consumerism mediates part of the effect of environmental concern on the acceptance of wind power, as also predicted by $\mathrm{H} 4$.

The significance of the partial mediation of the effect of environmental concern through green consumerism can be tested by comparing two models of the relationship between environmental concern and acceptance of wind power while excluding green consumerism from the analysis: a model where the effect from environmental concern to acceptance of wind power is fixed to its estimated value in Table 2 and a model where this path is set free. The chi-square difference between these two models is 3.702 with $1 \mathrm{df}$, which is significant at $p=.05$. 
In sum, the study shows that the acceptance of expanding wind power in Maine not only depends on people's problem awareness, as reflected in their environmental concern. When controlling for environmental concern, people who are more actively engaged in doing small and simple things for the environment in their everyday life, termed "green consumerism" in this article, are more likely to accept an expansion of wind power than people who are less engaged in everyday "green" activities. The standardized regression coefficients in Table 2 suggest that the size of the direct impact of "green consumerism" is about two third of the direct impact and about half of the total impact of environmental concern. About a fifth of the total impact of environmental concern on the acceptance of wind power is mediated through "green consumerism."

\section{DISCUSSION}

Our analysis has led us to two rather broad conclusions, and a set of research questions for future investigations. Our preliminary purpose in pursuing this analysis was to determine whether it appeared that the "wedge" effect, or the reverse, dominated for individuals who engage in small, everyday pro-environmental behaviours when considering more impactful behaviours, including acceptance of wind power, as an example of necessary environmental policy or infrastructure change. Our evidence suggests that individuals experience a positive spillover (i.e., "wedge") effect regarding the acceptance of wind power in Maine to the extent that they have been actively performing behaviours that may be characterized as everyday "green consumerism." This conclusion is based on our finding that the positive correlation between "green consumerism" and acceptance of wind power is not just due to both being rooted in general environmental concern. If a person acts pro-environment, even in small and 
simple ways, this in itself seems to increase their acceptance of and support for wind power, over and above the effects of (just) being environmentally concerned.

Our empirical study is mute about exactly why a positive spillover occurs from "green" everyday behaviours to the acceptance of wind power. It stands to reason that a positive spillover such as this is the product of some kind of action-based learning, but many different types of learning may be involved, including experience-based knowledge acquisition, increased goal salience and strengthening of the person's "environmentalist" self-perception or identity.

Reflections of the causes of behavioural spillover are suggestive regarding the role of information in this connection. It is often argued that improved information on environmental issues will not in itself cause individuals to "automatically act to reduce their energy consumption and carbon footprint" (Moser, 2010, p. 36). We agree with that. However, that does not mean that information provision is unimportant, on the contrary (Ockwell et al., 2009). Since the most serious environmental problems currently facing humanity, including global warming, are often not directly perceptible through our senses, information is needed to create environmental awareness or concern, and a certain level of environmental awareness or concern is in turn needed to motivate both most everyday pro-environmental behaviours and the voluntary acceptance of more drastic policy measures to protect the environment. However, our research suggests that the impact of information campaigns on environmental behaviour may sometimes take a longer path than is usually considered. Further, although in and of themselves the small changes in everyday "green" behaviour that are often the specific goal of environmental campaigns are relatively inconsequential, they may provide a "wedge" to behaviour changes with greater environmental impacts, such as a higher acceptance of ambitious infrastructure changes towards renewable energy. Hence, the promotion of everyday "green" behaviours may 
lay the foundation for increasing the public's acceptance of more far-reaching changes. This is consistent with the notion that the issue is not knowledge itself, but behaving the right way with the knowledge (Norgaard, 2011).

An important issue discussed in the reviewed literature is that, because many pro-environmental behaviours are common, socially mandated, or provide private side-benefits, individuals may no longer consider these behaviours as particularly pro-environmental. In these cases, the reviewed literature suggests that the likelihood of spillover to more impactful pro-environmental behaviours may be enhanced by messaging that such common or motivationally ambiguous behaviours are indeed pro-environmental (Cornelissen et al., 2007; Cornelissen et al., 2008; Evans et al., In press). Consistent with this, recent goal-priming research shows that when people think about a motivationally ambiguous behaviour in environmental terms, environmental goals are made more accessible in the person's mind and are therefore more likely to guide the person's behaviour in other environmentally relevant situations (Evans et al., In press). Together, these streams of research imply that, in order to reap the full spillover potential from "green" everyday behaviour, the promotion of such behaviour should be motivated by environmental reasons, or combined with reminders that the promoted behaviours are indeed "green."

\section{Limitations}

We recognize the cultural circumstances that divide our world. In an American context, Maine is known for a cohesive state identity and strong environmental values (Anderson et al., 2012). Future replicative research in a variety of cultures and circumstances would be most instructive to this line of inquiry. Moreover, wind power in Maine probably represents a situation of greater 
salience to the individuals surveyed than many other environmental policy proposals or infrastructure projects. Among other things, this means that it is challenging to disentangle the private benefits (for example with wind power: decreased property tax, increased economic activity) and costs (for example: loss of aesthetics, wildlife and recreational impacts) from the social benefits of increased renewable energy supply.

Further, although we have taken great precautions to avoid statistical artefacts and control for shared antecedents that might account for the positive correlation between green consumerism and the acceptance of wind power and although the included antecedents logically precede the acceptance of wind power, our data are still limited to a single cross sectional survey. Hence, although our data are consistent with the hypothesized causal relationship between green everyday behaviour and the acceptance of wind power, we cannot prove the causal relationship with these data.

Future research

Our investigation leads us to raise additional research questions as well.

What is the set of small pro-environmental behaviour that may act as "wedges" for larger changes? Already in 2008, the UK government's Department for Environment, Food and Rural Affairs, Defra, called for research identifying such "wedge" (or catalytic) behaviours, and the question is still open (Defra, 2008). As argued by Thøgersen and Crompton (2009), perhaps the right question is not which behaviours can most effectively serve as a "wedge," but under which circumstances simple everyday "green" behaviours may serve as a wedge, also implying that different behaviours may serve as a wedge under different circumstances. Notably, the entanglement of pro-environmental behaviour's private and social benefits makes the 
identification of potential "wedge" behaviours more challenging. We also call for future research into better understanding the micro-processes of spillover from one pro-environmental behaviour to another, including circumstances in which information yields increased environmental awareness, where it translates into low-impact environmental behaviours by individuals, and where it spills over into more impactful behaviours. We especially welcome experimental research that is able to map out the causal connections in these micro-processes.

In general our work provides a new piece of the pro-environmental behaviour puzzle: evidence substantiating the "wedge" effect in an important case. Understanding the complex relationship between information, environmental concern and environmental behaviour as an antecedent to accepting necessary environmental policy, including major infrastructure changes, may allow for more effective information to action translation. Hence, although insights about such spillover effects may not ease the challenging task of persuasively communicating complex environmental issues, such as climate change (Moser, 2010), it may help campaigners design interventions that facilitate the path from problem awareness to accepting effective policies to target these issues.

\section{ACKNOWLEDGEMENTS}

This research was conducted as part of Maine's Sustainability Solutions Initiative, supported by National Science Foundation award EPS-0904155 to Maine EPSCoR at the University of Maine. We are grateful for insightful comments on an earlier draft of this paper from two anonymous reviewers. 
FIGURES

Fig. 1. Environmental concern, green consumerism, and the acceptance of wind power. (For interpretation of the references to color in this figure legend, the reader is referred to the web version of this article.)

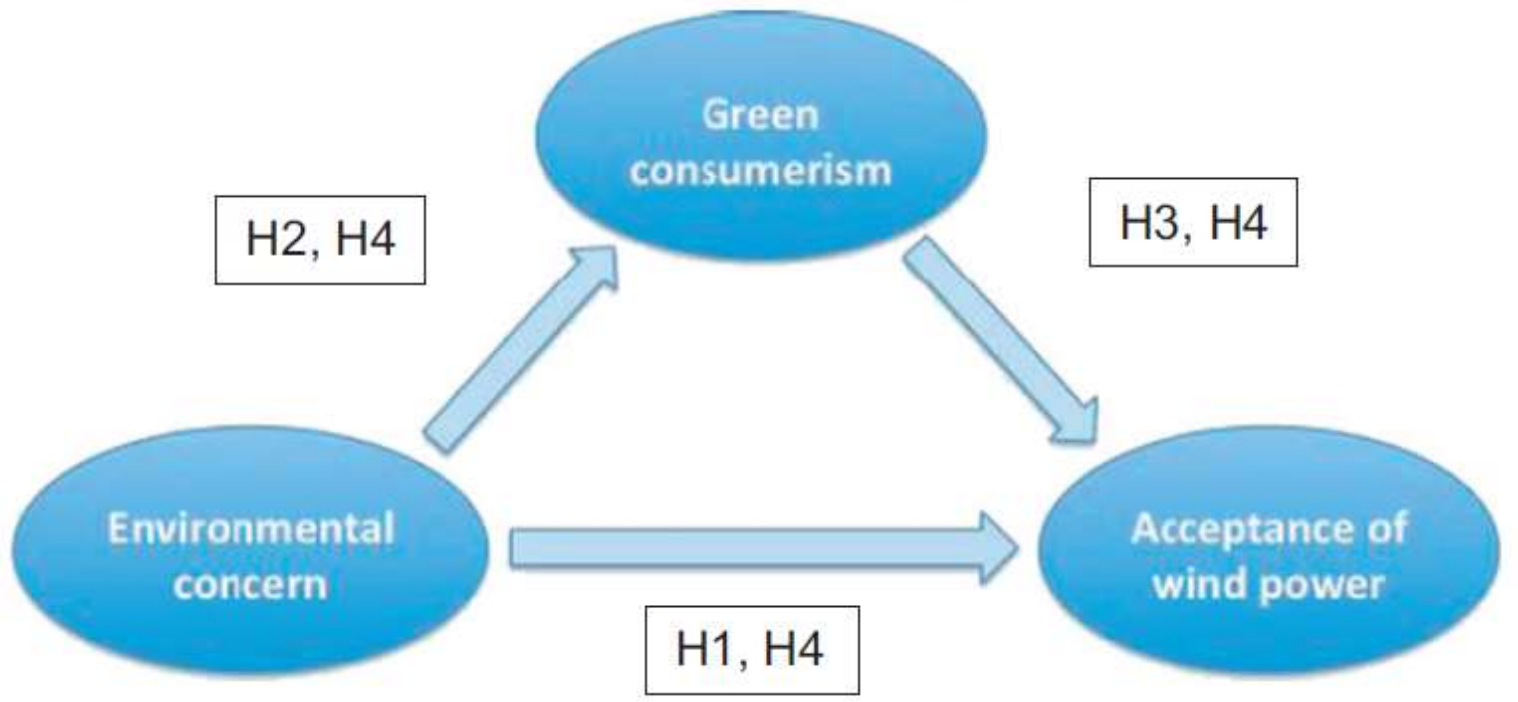




\section{Table 1}

Factor loadings and correlations between latent factors based on CFA, $N=613$.

Factor loadings

(standardized)

\begin{tabular}{ll}
\hline Acceptance of wind power & \\
- & .91 \\
- & .89 \\
Green consumerism & .57 \\
- & .60 \\
- & .67 \\
Environmental concern & .64 \\
- & .56 \\
- & .60 \\
- & .83 \\
- & .85 \\
- & .63 \\
& Correlations \\
Green consumerism-Accept wind power & .36 \\
Envir concern-Accept wind power & .44 \\
Envir concern-Green consumerism & .42 \\
\hline
\end{tabular}

Note: Test statistics: Chi-square $=181.952,51 \mathrm{df} ., p<.001 . \mathrm{CFI}=.96, \mathrm{RMSEA}=.065$ (90\% confidence interval:.055-.075). All factor loadings and correlations are significant, $p<.001$. 


\section{Table 2}

Structural relations between the acceptance of wind power, environmental concern and green consumerism, $N=613$.

\begin{tabular}{|c|c|c|c|}
\hline & & $\begin{array}{l}\text { Unstandardized } \\
\text { regression } \\
\text { coefficient }\end{array}$ & $\begin{array}{l}\text { Standardized } \\
\text { regression } \\
\text { coefficient }\end{array}$ \\
\hline Accept WP & $\begin{aligned}<- & \text { Green } \\
& \text { consumerism }\end{aligned}$ & .50 & .21 \\
\hline Accept WP & $\begin{aligned}<- & \text { Environmental } \\
& \text { concern }\end{aligned}$ & .50 & .35 \\
\hline $\begin{array}{l}\text { Green } \\
\text { consumerism }\end{array}$ & $\begin{aligned}<- & \text { Environmental } \\
& \text { concern }\end{aligned}$ & .25 & .42 \\
\hline Indirect effects & & & \\
\hline Accept WP & $\begin{aligned}<- & \text { Environmental } \\
& \text { concern }\end{aligned}$ & .12 & .09 \\
\hline \multicolumn{4}{|l|}{ Total effects } \\
\hline Accept WP & $\begin{aligned}<- & \text { Environmental } \\
& \text { concern }\end{aligned}$ & .63 & .44 \\
\hline$R^{2}$ accept WP & & .23 & \\
\hline $\begin{array}{l}R^{2} \text { green } \\
\text { consumerism }\end{array}$ & & .18 & \\
\hline
\end{tabular}

Note: Test statistics: Chi-square $=181.952,51$ df., $p<.001 . \mathrm{CFI}=.96, \mathrm{RMSEA}=.065$ (90\% confidence interval:.055-.075). All regression coefficients are significant, $p<.001$. 


\section{REFERENCES}

Anderson, M., Noblet, C., Teisl, M., 2012. Our environment: a glimpse at what Mainers value. Maine Policy Review 21 (1), 104-109.

Arbuckle, J.L., 2006. Amos 7.0 User's Guide. Chicago: SPSS.

Baron, R.M., Kenny, D.A., 1986. The moderator-mediator variable distinction in social psychological research: conceptual, strategic, and statistical considerations. Journal of Personality and Social Psychology 51, 1173-1182.

Barr, S., 2006. Environmental action in the home: investigating the "value-action" gap. Geography 91, 43-54.

Beaman, A.L., Cole, C.M., Preston, M., Klentz, B., Steblay, N.M., 1983. Fifteen years of foot-in-the door research. A meta-analysis. Personality and Social Psychology Bulletin 9 (2), 181-196.

Bell, D., Gray, T., Haggett, C., 2005. The "social gap" in wind farm siting decisions: explanations and policy responses. Environmental Politics 14, 460-477.

Bem, D.J., 1972. Self-perception theory. In: Berkowitz, L. (Ed.), Advances in Experimental Social Psychology. Academic Press, New York, pp. 1-62.

Biel, A., Dahlstrand, U., Grankvist, G., 2005. Habitual and value-guided purchase behavior. Ambio 34 (4-5), 360-365.

Bollen, K.A., 1989. Structural Equations with Latent Variables. Wiley-Interscience, New York.

Bosley, P., Bosley, K., 1988. Public acceptability of California's wind energy developments: three studies. Wind Engineering 12 (5), 311-318.

Bratt, C., 1999. Consumers' environmental behavior: generalized, sector-based, or compensatory? Environment and Behavior 31, 28-44.

Breukers, S., Wolsink, M., 2007. Wind power implementation in changing institutional landscapes: an international comparison. Energy Policy 35 (5), 2737-2750.

Cornelissen, G., Dewitte, S., Warlop, L., Yzerbyt, V., 2007. Whatever people say I am, that's what I am: social labeling as a social marketing tool. International Journal of Research in Marketing 24 (4), 278-288.

Cornelissen, G., Pandelaere, M., Warlop, L., Dewitte, S., 2008. Positive cueing: promoting sustainable consumer behavior by cueing common environmental behaviors as environmental. International Journal of Research in Marketing 25 (1), 46-55.

Crompton, T., 2008. Weathercocks and Signposts. The Environment Movement at a

Crossroads. WWF-UK, Surrey. Defra, 2008. A Framework for Pro-environmental Behaviours. DEFRA, London. Devine-Wright, P., 2005. Beyond NIMBYism: towards an integrated framework for understanding public perceptions of wind energy. Wind Energy 8 (2), 125-139.

Dhar, R., Simonson, I., 1999. Making complementary choices in consumption episodes: highlighting versus balancing. Journal of Marketing Research 36, 29-44.

Dietz, T., Gardner, G.T., Gilligan, J., Stern, P.C., Vandenbergh, M.P., 2009. Household actions can provide a behavioral wedge to rapidly reduce U.S. carbon emissions. Proceedings of the National Academy of Sciences (PNAS) 106 (44), 18452-18456.

Dillman, D., Smyth, J., Christian, J., 2009. Internet, Mail, and Mixed-mode Surveys: The Tailored Design method, third ed. Wiley, Hoboken, NJ.

Dunlap, R.E., 2008. The new environmental paradigm scale: from marginality to worldwide use. Journal of Environmental Education 40 (1), 3-18.

Dunlap, R.E., Van Liere, K.D., 1978. The "new environmental paradigm": a proposed measuring 
instrument and preliminary results. Journal of Environmental Education 9, 10-19.

Dunlap, R.E., Van Liere, K.D., Mertig, A.G., Jones, R.E., 2000. New trends in measuring environmental attitudes: measuring endorsement of the new ecological paradigm: a revised NEP scale. Journal of Social Issues 56 (3), 425-442.

Eriksson, L., Garvill, J. r., Nordlund, A.M., 2006. Acceptability of travel demand management measures: the importance of problem awareness, personal norm, freedom, and fairness. Journal of Environmental Psychology 26 (1), 15-26.

Evans, L., Maio, G. R., Corner, A., Hodgetts, C. J., Hahn, U., and Ahmed, S. Self-interest and Pro-environmental Behaviour. Nature Climate Change. http://dx. doi.org/10.1038/nclimate1662, in press.

Festinger, L., 1957. A Theory of Cognitive Dissonance. Row Peterson, Evanston.

Firestone, J., Kempton, W., Krueger, A., 2009. Public acceptance of offshore wind power projects in the USA. Wind Energy 12 (2), 183-202.

Fransson, N., Gärling, T., 1999. Environmental concern: conceptual definitions, measurement methods, and research findings. Journal of Environmental Psychology 19, 369-382.

Freedman, J., Fraser, S., 1966. Compliance without pressure: the foot-in-the-door technique. Journal of Personality and Social Psychology 4, 195-202.

Futerra. (2006). New Rules: New game-Communications tactics for climate change Available from /http://tinyurl.com/ yoj92vS.

Glasman, L.R., Albarraci'n, D., 2006. Forming attitudes that predict future behavior: a meta-analysis of the attitude-behavior relation. Psychological Bulletin 132 (5), 778-822.

Gross, C., 2007. Community perspectives of wind energy in Australia: the application of a justice and community fairness framework to increase social acceptance. Energy Policy 35 (5), 2727-2736.

Guagnano, G.A., Dietz, T., Stern, P.C., 1994. Willingness to pay for public goods: a test of the contribution model. Psychological Science 5, 411-415.

GWEC. (2011). Global Wind Report-Annual Market Update 2010. Brussels: Global Wind Energy Council.

Haggett, C., 2011. Understanding public responses to offshore wind power. Energy Policy 39 (2), 503-510.

Jansson, J., Marell, A., Nordlund, A., 2010. Green consumer behavior: determinants of curtailment and eco-innovation adoption. Journal of Consumer Marketing 27, 358-370.

Jobert, A., Laborgne, P., Mimler, S., 2007. Local acceptance of wind energy: factors of success identified in French and German case studies. Energy Policy 35 (5), 2751-2760.

Johnston, R., Swallow, S., Tyrrell, T., Bauer, D, 2003. Rural amenity values and length of residency. American Journal of Agricultural Economics 85, 1000-1015.

Kahneman, D., Ritov, I., Jacowitz, K.E., 1993. Stated willingness to pay for public goods: a psychological perspective. Psychological Science 4, 310-316.

Kaiser, F.G., Wilson, M., 2004. Goal-directed conservation behavior: the specific composition of a general performance. Personality and Individual Differences 36, 1531-1544.

Keller, J. (2010). Can Wind Power Survive the NIMBY Syndrome? The Atlantic, (April 20). Retrieved from /http://www.theatlantic.com/personal/archive/ 2010/04/can-wind-power-survive-the-nimby-syndrome/39251/S.

Kim, J., Kim, Y., 2010. Psychological make-up of Korean green consumerism: a path model analysis. Journal of Global Academy of Marketing Science 20, 249-261.

Knussen, C., Yule, F., MacKenzie, J., Wells, M., 2004. An analysis of intentions to recycle household waste: the roles of past behaviour, perceived habit, and perceived lack of facilities. Journal of Environmental Psychology 24 (2), 237-246. 
Marques, A.C., Fuinhas, J.A., 2011. Drivers promoting renewable energy: a dynamic panel approach. Renewable and Sustainable Energy Reviews 15 (3), 1601-1608.

Mazar, N., Zhong, C.-B., 2010. Do green products make us better people? Psychological Science $21,494-498$.

McKay, D. (2008). Sustainable Energy - without the hot air. Available from http:// www.withouthotair.coms.

Moisander, J., 2007. Motivational complexity of green consumerism. International Journal of Consumer Studies 31 (4), 404-409.

Moser, S.C., 2010. Communicating climate change: history, challenges, process and future directions. Wiley Interdisciplinary Reviews: Climate Change 1 (1), 31-53.

Nigg, C.R., Allegrante, J.P., Ory, M., 2002. Theory-comparison and multiple-behavior research: common themes advancing health behavior research. Health Education Research 17 (5), 670-679.

Nigg, C.R., Burbank, P.M., Padula, C., Dufresne, R., Rossi, J.S., Velicer, W.F., et al., 1999. Stages of change across ten health risk behaviors for older adults. The Gerontologist 39 (4), 473482.

Noar, S.M., Chabot, M., Zimmerman, R.S., 2008. Applying health behavior theory to multiple behavior change: considerations and approaches. Preventive Medicine 46 (3), 275-280.

Norgaard, K.M., 2011. Living in Denial: Climate Change, Emotions, and Everyday Life, Boston, MA. MIT Press.

Ockwell, D., Whitmarsh, L., O'Neill, S., 2009. Reorienting climate change communication for effective mitigation. Science Communication 30, 305-327.

Pasqualetti, M.J., 2011. Opposing wind energy landscapes: a search for common cause. Annals of the Association of American Geographers 101 (4), 907-917.

Rasinski, K.A., Lee, L., Krishnamurty, P., 2012. Question order effects. In: Cooper, H., Camic, P.M., Long, D.L., Panter, A.T., Rindskopf, D., Sher, K.J. (Eds.), APA Handbook of Research Methods in Psychology, Vol 1: Foundations, Planning, Measures, and Psychometrics. American Psychological Association, Washington, DC, pp. 229-248.

Ratneshwar, S., Barsalou, L.W., Pechmann, C., Moore, M., 2001. Goal-derived categories: the role of personal and situational goals in category representations. Journal of Consumer Psychology 10, 147-157.

Revans, R., 2011. ABC of Action Learning. Gower, Farnham, UK.

Reynolds, M., Vince, R., 2004. Critical management education and action-based learning: synergies and contradictions. Academy of Management Learning and Education 3, 442-456.

Russell, B. (2008. 1 January). 'Nimbyism' Blocking the Spread of Wind Farms. The Independent.

Stern, P.C., 2000. Towards a coherent theory of environmentally significant behavior. Journal of Social Issues $56,407-424$.

Stern, P.C., Dietz, T., Abel, T., Guagnano, G.A., Kalof, L., 1999. A value-belief-norm theory of support for social movements: the case of environmentalism. Human Ecology Review 6, 8197.

Thøgersen, J., 1999. Spillover processes in the development of a sustainable consumption pattern. Journal of Economic Psychology 20, 53-81.

Thøgersen, J., 2004. A cognitive dissonance interpretation of consistencies and inconsistencies in environmentally responsible behavior. Journal of Environmental Psychology 24, 93-103.

Thøgersen, J. (2011, 22 March). Do small green actions lead to bigger ones - or to lying and stealing? the Guardian. Retrieved from /http://www.guardian.co. uk/sustainable-businessS.

Thøgersen, J., Crompton, T., 2009. Simple and painless? The limitations of spillover in environmental campaigning. Journal of Consumer Policy 32, 141-163. 
Thøgersen, J., O“ lander, F., 2001. Transfer of Environment-Friendly Conduct Between Behavioural Categories. Paper presented at the 26th colloquium on research in economic psychology, Bath, 6-10 September.

Thøgersen, J., O“ lander, F., 2003. Spillover of environment-friendly consumer behavior. Journal of Environmental Psychology 23, 225-236.

Thøgersen, J., O * lander, F., 2006. To what degree are environmentally beneficial choices reflective of a general conservation stance? Environment and Behavior 38, 550-569.

Tucker, M., Reicks, M., 2002. Exercise as a gateway behavior for healthful eating among older adults: an exploratory study. Journal of Nutrition Education and Behavior 34 (Supplement 1), S14-S19.

U.S. Census Bureau. (2012, January). State and country quickfacts: Maine. Retrieved 4/26/12, from /http://quickfacts.census.gov/qfd/states/23000.htmlS.

van der Horst, D., 2007. NIMBY or not? Exploring the relevance of location and the politics of voiced opinions in renewable energy siting controversies. Energy Policy 35 (5), 2705-2714.

van Trijp, H.C.M., Fischer, A.R.H., 2011. Mobilizing consumer demand for sustainable development. In: van Latesteijn, H., Andeweg, K. (Eds.), The TransForum Model: Transforming Agro Innovation Toward Sustainable Development. Springer, Netherlands, pp. 73-96.

Verhoef, P.C., 2005. Explaining purchases of organic meat by Dutch consumers. European Review of Agricultural Economics 32, 245-267.

Verplanken, B., Holland, R.W., 2002. Motivated decision making: effects of activation and self-centrality of values on choices and behavior. Journal of Personality and Social Psychology 82, 434-447.

Wolsink, M., 2007. Planning of renewables schemes: deliberative and fair decision-making on landscape issues instead of reproachful accusations of non-cooperation. Energy Policy 35 (5), 2692-2704.

Wüstenhagen, R., Wolsink, M., B urer, M.J., 2007. Social acceptance of renewable energy innovation: an introduction to the concept. Energy Policy 35, 2683-2691.

Zhong, C.-B., Ku, G., Lount, R., Murnighan, J., 2010. Compensatory ethics. Journal of Business Ethics 92, 323-339. 